\title{
Avaliação da Aplicação de Jogos no Ensino de Programação: Uma Experiência Em Uma Disciplina Introdutória
}

\author{
Paulo Renato Conceição Mendes ${ }^{1}$, Pedro Vinícius Almeida de Freitas ${ }^{1}$, \\ Kassio Romulo Lima Sousa ${ }^{1}$, Carlos de Salles Soares Neto ${ }^{1}$ \\ ${ }^{1}$ TeleMídia/MA - Universidade Federal do Maranhão (UFMA) \\ São Luís - MA - Brasil \\ \{mendesdpn, pedropvaalmeida, romulo.kassio\}@gmail.com, csalles@deinf.ufma.br
}

\begin{abstract}
This work describes an evaluation of the use of serious games as a methodology for teaching programming concepts in an introdutory subject to programming. Six games were used in this discipline. These games were evaluated in a qualitative study, which was conducted with students of the subject, based on the games evaluation model Meega+. The results showed that the participants of the study found that the games helped them learn concepts of the subject.
\end{abstract}

Resumo. Este trabalho descreve a avaliação da aplicação de jogos como metodologia para o ensino de conceitos de programação em uma disciplina introdutória à programação. Para isso, foram empregados seis jogos na disciplina. Tais jogos foram avaliados em um estudo qualitativo, conduzido com alunos da disciplina, baseado no modelo de avaliação de jogos Meegat. Os resultados mostraram que os participantes do estudo avaliam que os jogos contribuíram para a aprendizagem deles na disciplina.

\section{Introdução}

Parte dos alunos iniciantes em cursos de tecnologia da informação possuem dificuldade para assimilar conceitos de lógica de programação, consequentemente, um considerável número acaba desistindo por conta da complexidade, dificuldades na abstração do aprendizado ou devido aos modelos tradicionais de ensino, que não se adequam às novas técnicas para estimular e despertar interesse nestes novos alunos [Silveira and Alcântara 2014]. Neste ambiente, "O uso de jogos educacionais para o ensino de computação vem se mostrando uma estratégia instrucional eficaz, que conduz os alunos à uma aprendizagem ativa e divertida" [Battistella and von Wangenheim 2016], criando uma alternativa eficaz para estimular e ensinar lógica de programação.

Assim, visando estimular o aprendizado dos alunos em uma disciplina de introdução a programação, explorando uma diferente didática para o ensino de programação, este trabalho tem como objetivo avaliar o emprego de jogos como uma ferramenta auxiliar para o ensino de tópicos de programação.

Dessa forma, este trabalho apresenta um estudo qualitativo do uso de jogos no ensino de programação. Assim, a partir de uma entrevista com professores da disciplina, foram levantados os tópicos presentes na mesma. Com base nesses tópicos, foram selecionados jogos que abordassem alguns deles, de modo que todos os tópicos fossem abordados por pelo menos um jogo. Foram selecionados seis jogos, que foram aplicados 
VII Congresso Brasileiro de Informática na Educação (CBIE 2018)

Anais do XXIX Simpósio Brasileiro de Informática na Educação (SBIE 2018)

e avaliados em uma disciplina introdutória à programação de um curso de bacharelado em Ciência da Computação, e avaliou-se a percepção de aprendizagem dos alunos em relação aos jogos e o emprego desses jogos como metodologia de ensino.

Para descrever esse processo, este trabalho está organizado como se segue. Seção 2 elenca alguns trabalhos relacionados a este. Seção 3 descreve a metodologia adotada neste trabalho. Seção 4 detalha os resultados colhidos. Seção 5 discute e faz observações sobre os resultados obtidos.

\section{Trabalhos Relacionados}

Alguns jogos e iniciativas voltadas ao ensino de programação de forma lúdica que tentam despertar o interesse de iniciantes no mundo da computação são as seguintes ferramentas: ALGO+, Desafio da Serpente e Pirâmide Multiplicativa. Tais ferramentas foram encontradas em artigos publicados no Simpósio Brasileiro de Informática na Educação (SBIE), tendo como foco a busca por artigos baseados no uso de jogos ou elementos lúdicos para o ensino de lógica e programação.

$A L G O+$ é uma ferramenta de apoio ao processo de ensino e aprendizagem de lógica e programação, voltado para alunos iniciantes [Amaral et al. 2017]. O ALGO+ foi aplicado em duas turmas de Algoritmos e Programação. O portal obteve um resultado inicial em que os alunos mantiveram as médias de suas notas, tanto os que utilizaram a estrutura e conteúdo do portal quanto os que não o utilizaram. O principal ganho observado foi o fato de que o portal manteve o interesse e a qualidade de ensino sem a necessidade de um tutor direto, obtendo um desempenho similar ao obtido em sala de aula.

O Desafio da Serpente trata da aplicação de conceitos de gamificação para propor desafios diários para um grupo de alunos por oito semanas, medindo e tendo como resultado índices satisfatórios de comprometimento com estudos e aceitação do públicoalvo [Raposo and Dantas 2016]. O objetivo principal do Desafio da Serpente é motivar os alunos de programação a criar uma rotina de estudo e se sentirem motivados a resolver questões de programação. O jogo obteve aceitação de $96 \%$ dos alunos e grande quantidade de submissões diárias, inclusive motivando alunos a realizarem atividades na plataforma em finais de semana.

Finalmente, o Pirâmide Multiplicativa é um jogo digital sério que tem o objetivo de ser uma alternativa para o ensino da tabuada através da utilização de ferramentas computacionais [Rolino et al. 2015]. O jogo foi aplicado com alunos de 11 e 14 anos, que fazem parte do segundo ciclo do ensino fundamental, auxiliando em suas dificuldades com o aprendizado da tabuada. Os docentes que utilizaram o jogo para o ensino da tabuada confirmaram o ganho quanto a instigar e motivar os alunos, dando uma nova dinâmica ao aprendizado.

\section{Métodos e Técnicas}

Este trabalho foi dividido em três fases distintas, cada uma produzindo um artefato que serviu como entrada para a fase seguinte. O fluxo de fases pode ser visto na Figura 1, e elas são detalhadas nas subseções 3.1, 3.2 e 3.3.

\subsection{Fase de Levantamento de Tópicos}

Nesta fase, foi feito um levantamento acerca dos tópicos da disciplina abordada por meio de uma entrevista com professores que ministraram tal disciplina. A partir dessa entre- 
VII Congresso Brasileiro de Informática na Educação (CBIE 2018)

Anais do XXIX Simpósio Brasileiro de Informática na Educação (SBIE 2018)

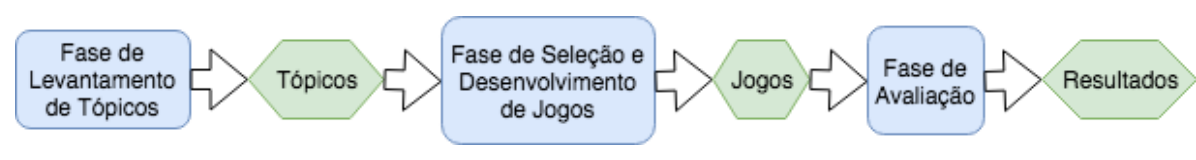

Figura 1. Fases Metodológicas

vista, sete tópicos foram levantados. Os tópicos levantados podem ser vistos na Tabela 1 .

Tabela 1. Tópicos principais de uma disciplina introdutória a programação.

\begin{tabular}{llll}
\hline \multicolumn{4}{c}{ Tópicos } \\
\hline$T 1$ & Sintaxe e Semântica & T5 & Laços de Repetição \\
\hline$T 2$ & Tipos de Dados & T6 & Vetores \\
\hline T3 & Álgebra de Boole & T7 & Busca Linear \\
\hline T4 & Estruturas Condicionais & \\
\hline
\end{tabular}

\subsection{Fase de Seleção e Desenvolvimento de Jogos}

A partir de então, foram selecionados quatro jogos feitos por ex alunos da disciplina que cobrissem um ou mais dos tópicos levantados. Entretanto, observou-se que alguns tópicos não haviam sido abordados por nenhum dos jogos. Por isso, focando na completude deste trabalho, desenvolveu-se dois novos jogos: Code Dungeon e Caça Bugs, de modo que todos os tópicos levantados estivessem no escopo de pelo menos um jogo. Os jogos selecionados podem ser vistos na Figura 2, e uma descrição de cada um deles nos parágrafos seguintes. A Tabela 2 mostra os jogos selecionados e os tópicos por eles abordados.

Tabela 2. Jogos e tópicos por eles abordados

\begin{tabular}{llllllll}
\hline Jogos/Tópicos & T1 & T2 & T3 & T4 & T5 & T6 & T7 \\
\hline Hanoi Tower & $\mathrm{X}$ & & & & & & \\
\hline Crossing Code & $\mathrm{X}$ & & & & & & \\
\hline Boolamp & & $\mathrm{X}$ & $\mathrm{X}$ & & & & \\
\hline Invade the System & & $\mathrm{X}$ & & & & & \\
\hline Code Dungeon & $\mathrm{X}$ & $\mathrm{X}$ & $\mathrm{X}$ & $\mathrm{X}$ & $\mathrm{X}$ & $\mathrm{X}$ & $\mathrm{X}$ \\
\hline Caça Bugs & & & $\mathrm{X}$ & $\mathrm{X}$ & $\mathrm{X}$ & $\mathrm{X}$ & $\mathrm{X}$ \\
\hline
\end{tabular}

Hanoi Tower[Drummond and Melo 2014b] é um jogo educativo que consiste em uma plataforma contendo três ou mais pinos, em um dos quais são dispostos alguns discos uns sobre os outros, em ordem crescente de diâmetro, de cima para baixo. O jogo consiste em passar todos os discos de um pino para outro usando outros pinos como auxiliares, de maneira que nenhum disco maior fique em cima de outro menor ao fim da movimentação. Para realizar a movimentação de discos, o jogador usa uma sintaxe pré-informada. Seu objetivo é a avaliação do planejamento e raciocínio lógico e, principalmente, introduzir o jogador ao uso de regras sintáticas fixas[Silveira and Alcântara 2014].

Crossing Code[Drummond and Melo 2014a] é um jogo focado na introdução ao jogador na importância do uso correto de regras sintáticas pré-definidas. Para isso, o jogo pede que o aluno resolva o clássico problema de atravessar uma raposa, uma galinha e um saco de grãos de uma margem para outra de um rio. Tal tarefa é completada através de comandos utilizando uma sintaxe específica ensinada no jogo. 
VII Congresso Brasileiro de Informática na Educação (CBIE 2018)

Anais do XXIX Simpósio Brasileiro de Informática na Educação (SBIE 2018)

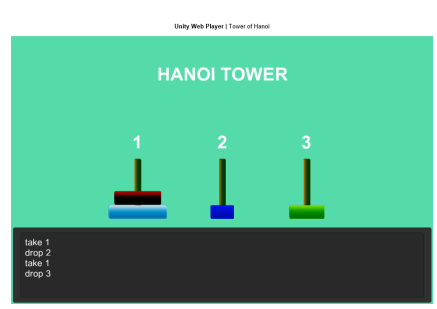

(a) Hanoi Tower

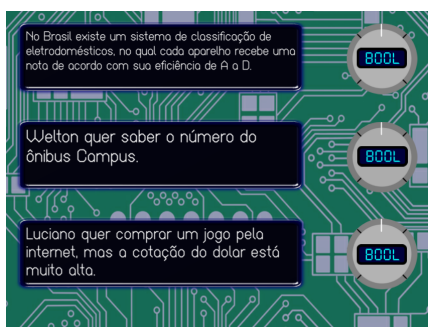

(d) Invade the System

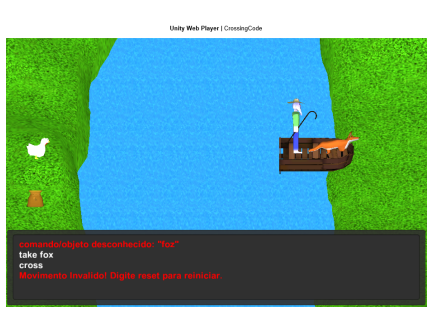

(b) Crossing Code (5) Code Dungeon

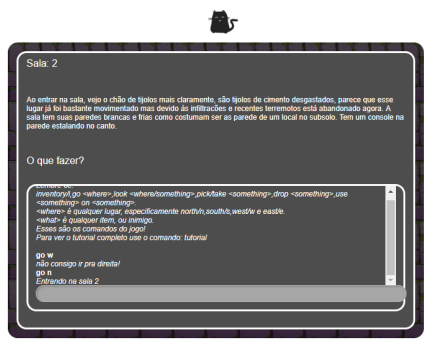

(e) Code Dungeon

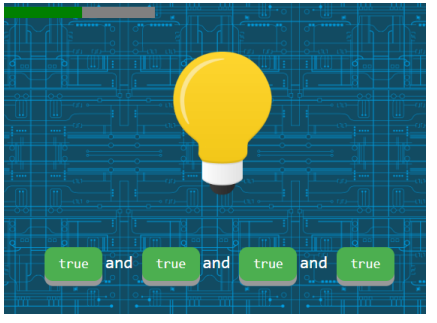

(c) Boolamp

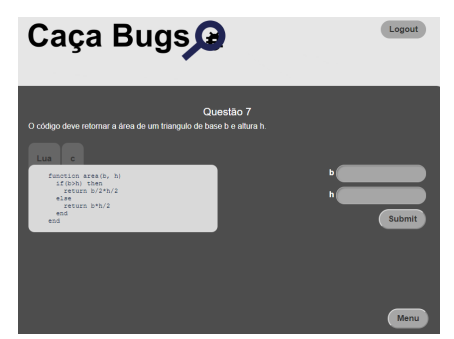

(f) Caça Bugs

Figura 2. Jogos Adotados no Estudo

Boolamp[Almeida 2016] é um jogo que também foca no raciocínio lógico do jogador porém de forma mais simplificada e competitiva. O desafio do jogo consiste em tornar verdadeiras a maior quantidade de expressões booleanas no menor tempo possível, dessa forma treinando o jogador na resolução de problemas utilizando álgebra de boole de forma rápida e mecânica.

Invade the System[Mendes et al. 2016] é um jogo que visa melhorar o entendimento do aluno em relação a tipos de dados (inteiro, real, booleano, string). Para isso são fornecidas situações cotidianas e o aluno deve identificar o tipo de dado mais adequado para cada uma das situações.

Code Dungeon[Almeida and Mendes 2016] é um jogo cujo objetivo é ensinar conceitos de programação misturando elementos de jogos de Role Playing Games(RPG) de texto. Nesse jogo, o usuário é colocado em um local com várias salas, as quais ele deve atravessar para chegar à saída. Para avançar a outras salas, o jogador utiliza e interage com itens como chaves, joias e ferramentas para destravar portas ou derrotar inimigos. $\mathrm{O}$ combate do jogo é feito através da resolução de problemas usando o Blockly[Fraser 2014] como método visual de programação e de resolução de problemas no jogo. Ao derrotar um inimigo ou destravar uma porta, o jogador tem acesso à uma ou mais salas adjacentes e pode continuar na exploração do mapa e desafios do jogo.

Caça Bugs[Mendes and Almeida 2016] é um jogo que visa reforçar a importância da qualidade de código e de interpretação de problemas computacionais. O jogo possui vários níveis, que abordam assuntos de programação como: estruturas de condição, repetição, cadeias de caractere e vetores. Em cada nível é fornecido um enunciado explicando o problema a ser revolvido e um código que deveria resolver o problema, mas possui erros. Para avançar de nível, o aluno deve fornecer entradas para o código que explorem os erros presentes no mesmo. 
VII Congresso Brasileiro de Informática na Educação (CBIE 2018)

Anais do XXIX Simpósio Brasileiro de Informática na Educação (SBIE 2018)

\subsection{Fase de Avaliação}

O estudo foi conduzido com alunos do primeiro período de um curso de Ciência da Computação durante as aulas de uma disciplina de introdução a programação. Um total de 36 alunos participaram do estudo, onde um possuía menos de 18 anos, 31, entre 18 e 28 anos, e os demais possuíam entre 29 e 39 anos. É importante ressaltar que nem todos os 36 participantes avaliaram todos os jogos presentes no estudo, uma vez que a avaliação de todos os jogos não ocorreu no mesmo dia e eventuais ausências de participantes ocorreram. Além da idade, também foi feito um levantamento da familiaridade dos participantes com jogos, de onde concluiu-se que mais de $60 \%$ dos participantes jogam pelo menos uma vez por semana.

Para a avaliação dos jogos, foi feito um estudo qualitativo do emprego deles. O estudo empírico foi separado por jogo, e foi composto por três fases distintas:

- Apresentação do Jogo: A finalidade dessa fase é apresentar as mecânicas e conceitos empregados no jogo, bem como aspectos relacionados à sua jogabilidade. Fazendo assim com que o participante se sinta confortável na utilização futura do jogo. Durante a apresentação de cada jogo, foi definido um objetivo de forma que o progresso no jogo perpassasse por todos os conceitos apresentados pelo jogo.

- Utilização do Jogo: Nessa fase, os participantes são convidados a jogarem e explorarem o jogo sendo avaliado por cerca de cinquenta minutos.

- Avaliação do Jogo: Os participantes são convidados a responderem o questionário de avaliação do jogo.

Devido à dificuldade de alunos iniciantes, o uso de tais jogos é avaliado considerando o engajamento e motivação destes alunos como forma de auxílio no ensino de programação [da Silva et al. 2014]. Para isso, foi utilizado um questionário baseado no modelo de avaliação de jogos Meega+[Petri et al. 2016]. Tal modelo fornece um extenso questionário de avaliação para ser utilizado pelos usuários do jogo. Dentre as questões fornecidas por esse modelo, foram selecionadas afirmações que avaliassem os seguintes aspectos: facilidade em jogar, nível de dificuldade do jogo, percepção de aprendizagem e diversão. Assim, obteve-se uma versão reduzida do Meega+, que foi utilizada no estudo empírico de avaliação. As afirmações selecionadas para a avaliação podem ser vistas na Tabela 3. Cada uma das afirmações possuía opções baseadas em uma escala Likert de cinco pontos [Vagias 2006]: 1 - Discordo Totalmente; 2 - Discordo; 3 - Nem discordo, nem concordo; 4 - Concordo; 5 - Concordo Totalmente.

Assim, os participantes do estudo foram convidados a responder o questionário baseado no questionário do Meega + com suas impressões a respeito dos jogos. Além do questionário, também pediu-se que os participantes elencassem pontos positivos dos jogos e sugerissem melhorias a estes. A avaliação dos jogos ocorreu de maneira satisfatória, de modo que eventuais problemas técnicos não atrapalhassem os participantes do estudo, e estes pudessem focar nos méritos do estudo. A Seção 4 discorre sobre os resultados obtidos dessa avaliação.

\section{Resultados}

Para avaliar a consistência interna dos dados coletados, foi calculado o coeficiente Alfa de Cronbach para cada um dos jogos. Os coeficientes alfa de cada jogo podem ser vistos na Tabela 4. 
VII Congresso Brasileiro de Informática na Educação (CBIE 2018)

Anais do XXIX Simpósio Brasileiro de Informática na Educação (SBIE 2018)

Tabela 3. Afirmações selecionadas do modelo Meega+ usadas na avaliação dos jogos.

\begin{tabular}{ll}
\hline & Afirmações \\
\hline A1 & Eu considero que o jogo é fácil de jogar. \\
\hline A2 & Este jogo é adequadamente desafiador para mim. \\
\hline A3 & Me sinto satisfeito com as coisas que aprendi no jogo. \\
\hline A4 & Eu me diverti com o jogo. \\
\hline A5 & É claro para mim como o conteúdo do jogo está relacionado com esta disciplina. \\
\hline A6 & O jogo é um método de ensino adequado para esta disciplina. \\
\hline A7 & Eu prefiro aprender com este jogo do que de outra forma (outro método de ensino). \\
\hline A8 & O jogo contribuiu para a minha aprendizagem na disciplina. \\
\hline A9 & O jogo foi eficiente para minha aprendizagem, em comparação com outras atividades da disciplina. \\
\hline
\end{tabular}

Tabela 4. Coeficientes alfa de consistência interna por jogo

\begin{tabular}{ccccccc}
\hline Jogo & Hanoi Tower & Crossing Code & Boolamp & Invade the System & Code Dungeon & Caça Bugs \\
\hline Alfa & 0.826 & 0.712 & 0.825 & 0.874 & 0.861 & 0.651
\end{tabular}

Observa-se que os coeficientes de todos os jogos possuem um valor maior que 0.61, que corresponde a um nível substancial de consistência interna [Landis and Koch 1977]. Denota-se ainda que a maior parte dos jogos avaliados possui um coeficiente maior que 0.80 , que corresponde a um nível excelente de consistência interna [Landis and Koch 1977].

Para tornar os resultados mais visíveis, eles são mostrados nas Figuras 3 a 8 em gráficos de barras sobrepostas, de modo que quantos mais para a direita estão as barras de um certo item do questionário, maior é a quantidade de participantes que concordam com tal item.

Os resultados da avaliação do jogo Hanoi Tower podem ser vistos na Figura 3. De acordo com os dados de tal figura, pode-se observar que a maioria dos participantes concordaram com os itens do questionário. $\mathrm{O}$ item A8 que diz "O jogo contribuiu para a minha aprendizagem na disciplina" não obteve discordâncias de participantes. Isso mostra que, na opinião dos participantes do estudo, o jogo Hanoi Tower contribuiu para a aprendizagem destes na disciplina. Quando solicitado que citasse pontos fortes do jogo Hanoi Tower, um participante citou que o jogo é "simples, prático e desafiador". Já na opinião de um outro participante, o jogo é "desafiador, estimulante e interessante".

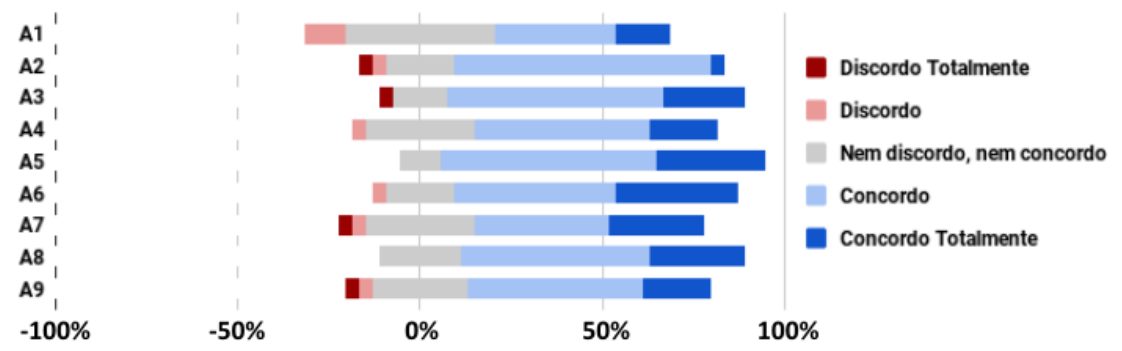

Figura 3. Resultados da avaliação do jogo Hanoi Tower

Já na avaliação do jogo Crossing Code observa-se que em afirmações como "É 
VII Congresso Brasileiro de Informática na Educação (CBIE 2018)

Anais do XXIX Simpósio Brasileiro de Informática na Educação (SBIE 2018)

claro para mim como o conteúdo do jogo está relacionado com a disciplina."(A5) e "O jogo é um método de ensino adequado para esta disciplina."(A6) não houveram discordâncias, sendo que para A5 todas as respostas foram concordo ou concordo totalmente. Por outro lado o item A2, "Este jogo é adequadamente desafiador para mim." foi a afirmação mais discordada pelos participante em relação aos outros itens sobre o jogo. Na avaliação dos participantes, o jogo é um método aceitável de ensino dos temas que apresenta, porém não desperta interesse ou senso competitivo para todos os participantes. Os resultados da avaliação do jogo Crossing Code podem ser vistos na Figura 4.
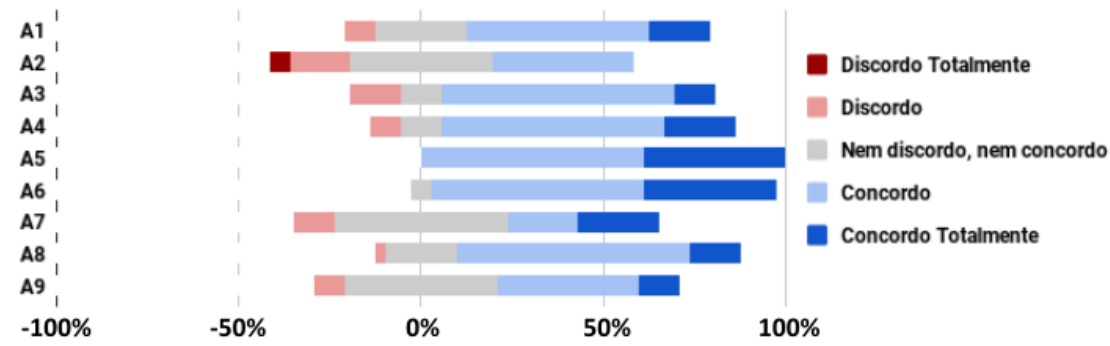

Figura 4. Resultados da avaliação do jogo Crossing Code

De acordo com os participantes, o jogo Boolamp é um jogo que apresenta satisfatoriamente os temas didáticos propostos, como visto nos resultados do gráfico da Figura 5, nos resultados dados nos itens A3 ("Me sinto satisfeito com as coisas que aprendi no jogo.") e A5 ("É claro para mim como o conteúdo do jogo está relacionado com a disciplina."). Apesar disso, não é considerado desafiador e fácil de jogar por todos participantes, como visto nos itens A1 e A2. Vale ressaltar também que houve respostas "Discordo Totalmente"nos itens A4 ("Eu me diverti com o jogo") e A7 ("Eu prefiro aprender com este jogo do que de outra forma (outro método de ensino)."). Sobre o Boolamp, um dos participantes o descreveu como "jogo muito bom para ajudar no desenvolvimento de pensamentos rápidos e lógico, assim como, para auxiliar no entendimento das variáveis booleanas.".
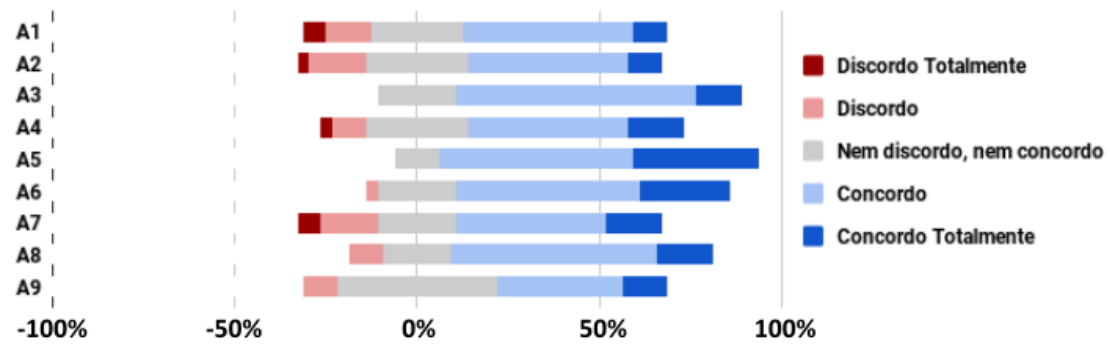

Figura 5. Resultados da avaliação do jogo Boolamp

Dentre os dados da avaliação do jogo Invade the System, pode-se observar que não houve discordâncias nos itens A3 ("Me sinto satisfeito com as coisas que aprendi no jogo."), A4 (“Eu me diverti com o jogo."), A5 ("É claro para mim como o conteúdo do jogo está relacionado com a disciplina.") e A6 ("O jogo é um método de ensino adequado para esta disciplina.") e discordâncias significativas em A1 ("Eu considero que o jogo é fácil de jogar.") e A7 ("Eu prefiro aprender com este jogo do que de outra forma (outro método de ensino)."). Dentre os pontos fortes sobre o jogo Invade the System segundo um dos participantes apresentam-se "conexão com a disciplina, raciocínio e diversão"e 
VII Congresso Brasileiro de Informática na Educação (CBIE 2018)

Anais do XXIX Simpósio Brasileiro de Informática na Educação (SBIE 2018)

dentre as sugestões de melhoria tem-se "Mais desafios, interações, objetivo mais claro". De acordo com os participantes, o jogo Invade the System é divertido, didático e se localiza bem no assunto apresentado, entretanto alguns participantes tiveram dificuldades em entender o jogo e não escolheriam esse jogo sobre outro método de ensino. Os resultados da avaliação do jogo Invade the System podem ser vistos na Figura 6.

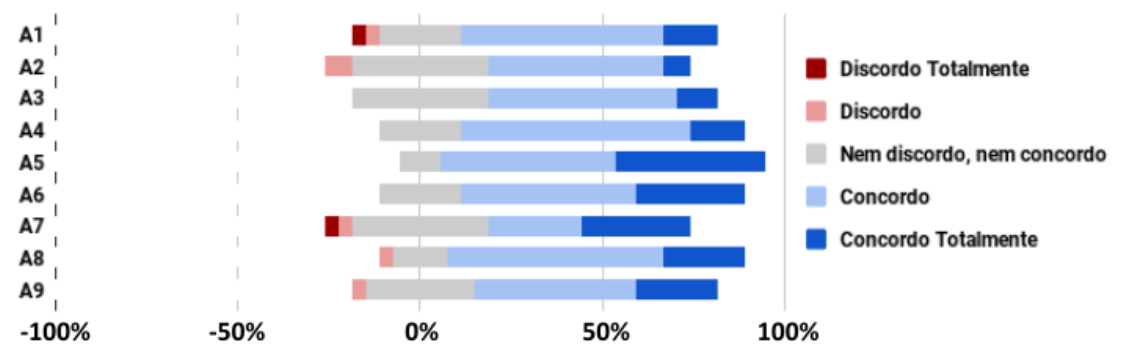

Figura 6. Resultados da avaliação do jogo Invade the System

Assim como nos jogos Invade the System e Boolamp, o jogo Code Dungeon obteve discordâncias notáveis em A1 ("Eu considero que o jogo é fácil jogar.") porém não obteve discordâncias em A2 ("Este jogo é adequadamente desafiador para mim.”),A8 (“O jogo contribuiu para a minha aprendizagem na disciplina.") e A9 ("O jogo foi eficiente para minha aprendizagem, em comparação com outras atividades da disciplina."). Conforme os participantes, o jogo contribui para a sua aprendizagem na disciplina, é adequadamente desafiador e é claro para eles como o conteúdo do jogo está relacionado a disciplina. Entre os comentários dos participantes se destacam "Desafiador, regras claras e comandos claros" e "Melhorar a intuitividade". Os resultados da avaliação do jogo Code Dungeon podem ser vistos na Figura 7.

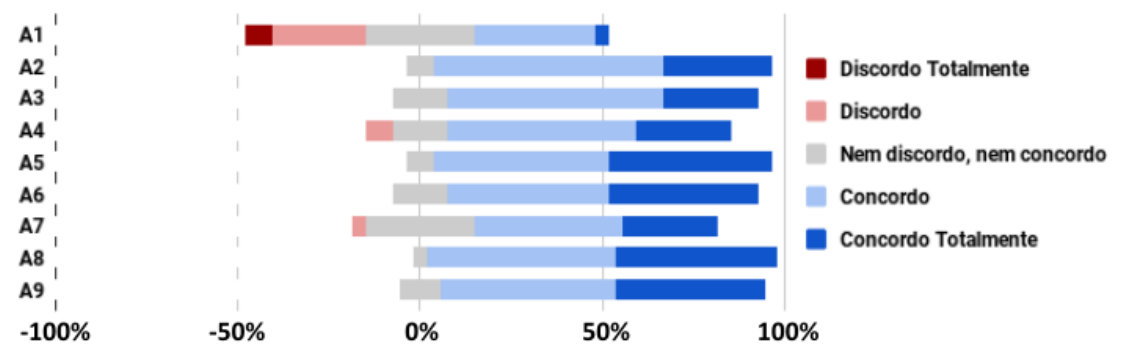

Figura 7. Resultados da avaliação do jogo Code Dungeon

Por fim, o jogo Caça Bugs é o jogo com o menor número de discordâncias, possuindo discordâncias apenas em A1 ("Eu considero que o jogo é fácil de jogar.") e A7 ("Eu prefiro aprender com este jogo do que de outra forma (outro método de ensino).") e concordâncias notáveis em A3 ("Me sinto satisfeito com as coisas que aprendi no jogo."), A5 ("É claro para mim como o conteúdo do jogo está relacionado com esta disciplina."), A6 ("O jogo é um método de ensino adequado para esta disciplina.") e A8 ("O jogo contribuiu para a minha aprendizagem na disciplina."). Consoante com os participantes, o jogo ensina satisfatoriamente, é clara a relação de seu conteúdo com o a disciplina, é um método adequado para a disciplina e contribui para o aprendizado da mesma."Instiga a compreensão de códigos, melhora o entendimento dos conteúdos e estimula o pensamento lógico" e "após alguma quantidades de erros, disponibilizar dicas" são alguns comentários a se destacar sobre o jogo. Os resultados da avaliação do jogo Caça Bugs 
VII Congresso Brasileiro de Informática na Educação (CBIE 2018)

Anais do XXIX Simpósio Brasileiro de Informática na Educação (SBIE 2018)

podem ser vistos na Figura 8.
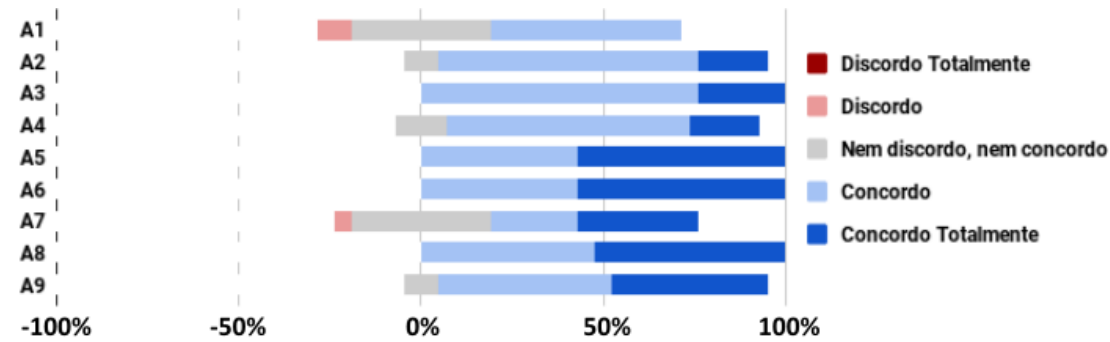

Figura 8. Resultados da avaliação do jogo Caça Bugs

\section{Considerações Finais}

Além da avaliação individual dos jogos utilizando um questionário baseado no Meega+, também foram feitas comparações entre os dados coletados de cada jogo. Dessa forma, pôde-se fazer inferências das preferências dos participantes.

Desconsiderando os itens A1 e A2, que dizem respeito, respectivamente, aos níveis de facilidade e desafio impostos pelos jogos e levando em conta os itens que se referem à percepção de aprendizagem e diversão (A3 a A8), observa-se que os jogos que obtiveram um maior índice de concordâncias foram os jogos Code Dungeon e Caça Bugs. Diferente dos demais jogos, que abordam assuntos específicos, esses jogos são mais abrangentes, abordando desde os assuntos iniciais até os finais da disciplina abordada.

O item A7 ("Eu prefiro aprender com este jogo do que outra forma (outro método de ensino)"), que apesar de obter um maior número de concordâncias em todos os jogos, não foi unanimidade em nenhum deles. Em todos os jogos avalidos houve pelo menos uma discordância no que diz respeito a esse item. Isso mostra que, na opinião dos participantes do estudo, o uso desses jogos como metodologia de ensino não é um consenso.

Finalmente, observa-se que, em todos os jogos avaliados, a maioria dos participantes concordaram com o item A8 ("O jogo contribuiu para a minha aprendizagem na disciplina"). Isso mostra que os participantes do estudo puderam aprender com os jogos, mas, como supramencionado, não necessariamente preferem essa metodologia de ensino.

O estudo qualitativo feito para avaliar o uso de jogos em uma disciplina de introdução a programação contribuiu para que significantes conclusões sobre o uso destes como metologia de ensino pudessem ser obtidas, mostrando que, em geral, os jogos foram bem avaliados e contribuíram para a aprendizagem dos participantes na disciplina. Como trabalho futuro, pretende-se incorporar mais jogos à disciplina, cobrindo mais tópicos da mesma, ainda de modo que possa ser conduzida uma avaliação mais abrangente do uso desse tipo de ferramenta como metodologia para o ensino de programação.

\section{Referências}

Almeida, D. (2016). Boolamp. Retrieved from: https://dayvsonalmeida.github.io.

Almeida, P. and Mendes, P. (2016). Code dungeon. Retrieved from: www.github.com/pedropva/CodeDungeon. 
VII Congresso Brasileiro de Informática na Educação (CBIE 2018)

Anais do XXIX Simpósio Brasileiro de Informática na Educação (SBIE 2018)

Amaral, E., Camargo, A., Gomes, M., Richa, C. H., and Becker, L. (2017). Algo+ uma ferramenta para o apoio ao ensino de algoritmos e programação para alunos iniciantes. In Brazilian Symposium on Computers in Education (Simpósio Brasileiro de Informática na Educação-SBIE), volume 28, page 1677.

Battistella, P. E. and von Wangenheim, C. G. (2016). Engaged: Um processo de desenvolvimento de jogos para ensinar computaçao. In Brazilian Symposium on Computers in Education (Simpósio Brasileiro de Informática na Educação-SBIE), volume 27, page 380.

da Silva, T. S. C., de AR Tedesco, P. C., and de Melo, J. C. (2014). A importância da motivação dos estudantes e o uso de técnicas de engajamento para apoiar a escolha de jogos no ensino de programação. In Brazilian Symposium on Computers in Education (Simpósio Brasileiro de Informática na Educação-SBIE), volume 25, page 11.

Drummond, G. and Melo, S. (2014a). Crossing code. Retrieved from: www.amagames.com.br/crossingcode.

Drummond, G. and Melo, S. (2014b). Hanoi tower. Retrieved from: www.amagames.com.br/hanoitower.

Fraser, N. (2014). Google blockly-a visual programming editor. URL: http://code. google. com/p/blockly. Accessed Aug.

Landis, J. R. and Koch, G. G. (1977). The measurement of observer agreement for categorical data. biometrics, pages 159-174.

Mendes, P. and Almeida, P. (2016). Caça bugs. Retrieved from: www.github.com/paulorcmendes/cacabugs.

Mendes, P., Almeida, P., Costa, C., and Marinho, W. (2016). Invade the system. Retrieved from: www.github.com/paulorcmendes/InvadeTheSystem.

Petri, G., von Wangenheim, C. G., and Borgatto, A. F. (2016). Meega+: an evolution of a model for the evaluation of educational games. INCoD/GQS, 3.

Raposo, E. H. S. and Dantas, V. (2016). O desafio da serpente-usando gamification para motivar alunos em uma disciplina introdutória de programação. In Brazilian Symposium on Computers in Education (Simpósio Brasileiro de Informática na EducaçãoSBIE), volume 27, page 577.

Rolino, J., Afini, D., and Vieira, G. (2015). Pirâmide multiplicativa: um jogo sério para a memorização da tabuada. In Brazilian Symposium on Computers in Education (Simpósio Brasileiro de Informática na Educação-SBIE), volume 26, page 617.

Silveira, R. P. and Alcântara, S. (2014). Relato da experiência do trabalho com jogos manuais de raciocínio lógico como reforço para as disciplinas de algoritmos e linguagem de programação. In Brazilian Symposium on Computers in Education (Simpósio Brasileiro de Informática na Educação-SBIE), volume 25, page 983.

Vagias, W. M. (2006). Likert-type scale response anchors. clemson international institute for tourism. \& Research Development, Department of Parks, Recreation and Tourism Management, Clemson University. 